\title{
Left Atrial size in Rheumatic Mitral Stenosis: An evaluation on the basis of age and heart rhythm
}

\author{
Yuba Raj Limbu*

\section{Introduction}

In Rheumatic Mitral Stenosis (MS) the left atrial size (LAD) increases with the increment of pressure gradient between the left atrium and left ventricle and the chance of left atrial mural thrombi increases with the increment of left atrial size ${ }^{1.2}$. Two-dimensional echocardiography is a well established technique to assess the left atrial size ${ }^{3}$, LAD is measured by M-mode echocardiography in the standard parasternal long axis view ${ }^{4}$ and enlarged LAD in rheumatic mitral stenosis is seen in echocardiography ${ }^{1.2}$.

Atrial fibrillation (AF) is commonly occurred complication in MS patients. Patients with AF tend to be older than those patients in normal sinus rhythm and established AF is usually accepted as a manifestation of advanced mitral stenosis that significantly influences the survival rates ${ }^{5.6}$. Left atrialsize and $A F$ are independent predictors of LA clot formation and systemic embolism in MS patients ${ }^{7.8}$. However the evaluation of enlarged LAD on the basis of age and heart rhythm among MS patients is unknown. This study mainly focuses on the evaluation of LAD on the basis of age and heart rhythm and aims to unveil the relation of $L A D$ and age and $L A D$ and heart rhythm in rheumatic mitral stenosis.

\section{Methods}

Study Subjects: One hundred seventy three patients with rheumatic mitral stenosis were recruited for the study. Age of the study subjects ranged from 10 to 79 years and mean \pm SD was $43.8 \pm 12.9$ years. Study subjects included 112 females $(6 S \%)$ and 61 males (3S\%). One hundred eight patients, 64 females and 44 males, were in atrial fibrillation and 6S patients, 48 females and 17 males were in normal sinus rhythm (NSR). Study subjects were further stratified on the basis of different age groups. The characteristics of study patients are given in table 1. 


\begin{tabular}{|ll|}
\hline Total Study Population & 173 \\
Female & $112(65 \%)$ \\
Male & $61(35 \%)$ \\
Age (year) + SD & $43.8 \pm 12.9$ \\
AF & 108 \\
SR & 65 \\
Age Group & \\
$<40$ year (AF/SR) & $58(20 / 38)$ \\
$40-50$ year (AF/SR) & $63(40 / 23)$ \\
$>50$ year (AF/SR) & $52(48 / 4)$ \\
\hline
\end{tabular}

\section{Table 1 Characteristics of Patients}

* Cardiologist Shahid Gangalal National Heart Centre, Kathmandu

SD: Standard Deviation, AF: Atrial fibrillation, SR: Sinus Rhythm

\section{Echocardiography and LAD measurement:}

The procedures of echocardiographic examinations were well performed in all study subjects. LAD was measured by Mmode echocardiography in the standard parasternal long axis view ${ }^{4}$. In all MS patients, MVA was directly measured in two-dimensional echocardiography ${ }^{9}$.

Statistical Analysis: Patients were divided into three age groups according to the age. Patients in age $<40$ years were assumed young patients and $40-50$ years age group was defined middle age group. Older than 50 years were considered older patients. Mean \pm SD of LAD was separately calculated in 173 study patients according to their age stratification; young, middle age and older age groups. Unpaired student's t-test was calculated to test the statistical significance of LAD among each age group. Correlation coefficient between LAD and age and LAD and MVA were calculated by linear regression arialysis. Finally unpaired student's t-test was calculated to determine the statistical significance of LAD, MVA and age difference between NSR and AF group. In the whole statistical analysis, statistical significance was considered when $\mathrm{P}<0.05$. 


\section{Results}

Comparison of LAD in three age groups (young, middle age and older): LAD was found significantly larger in older patients when compared with middle age and young patients, respectively $59 \pm 9.22 \mathrm{~mm}$ and $54.46 \pm 8.74 \mathrm{~mm}, \mathrm{P}<0.05$ and $59 \pm 9.22 \mathrm{~mm}$ and $53.8 \pm 10.22$ $\mathrm{mm}, \mathrm{P}<0.001$. The difference of LAD between middle age and young patients did not reach statistical significance $(54.46 \pm 8.74 \mathrm{~mm}$ and $53.8+10.22 \mathrm{~mm}, \mathrm{P}>0.5)$, see Fig. 1 .

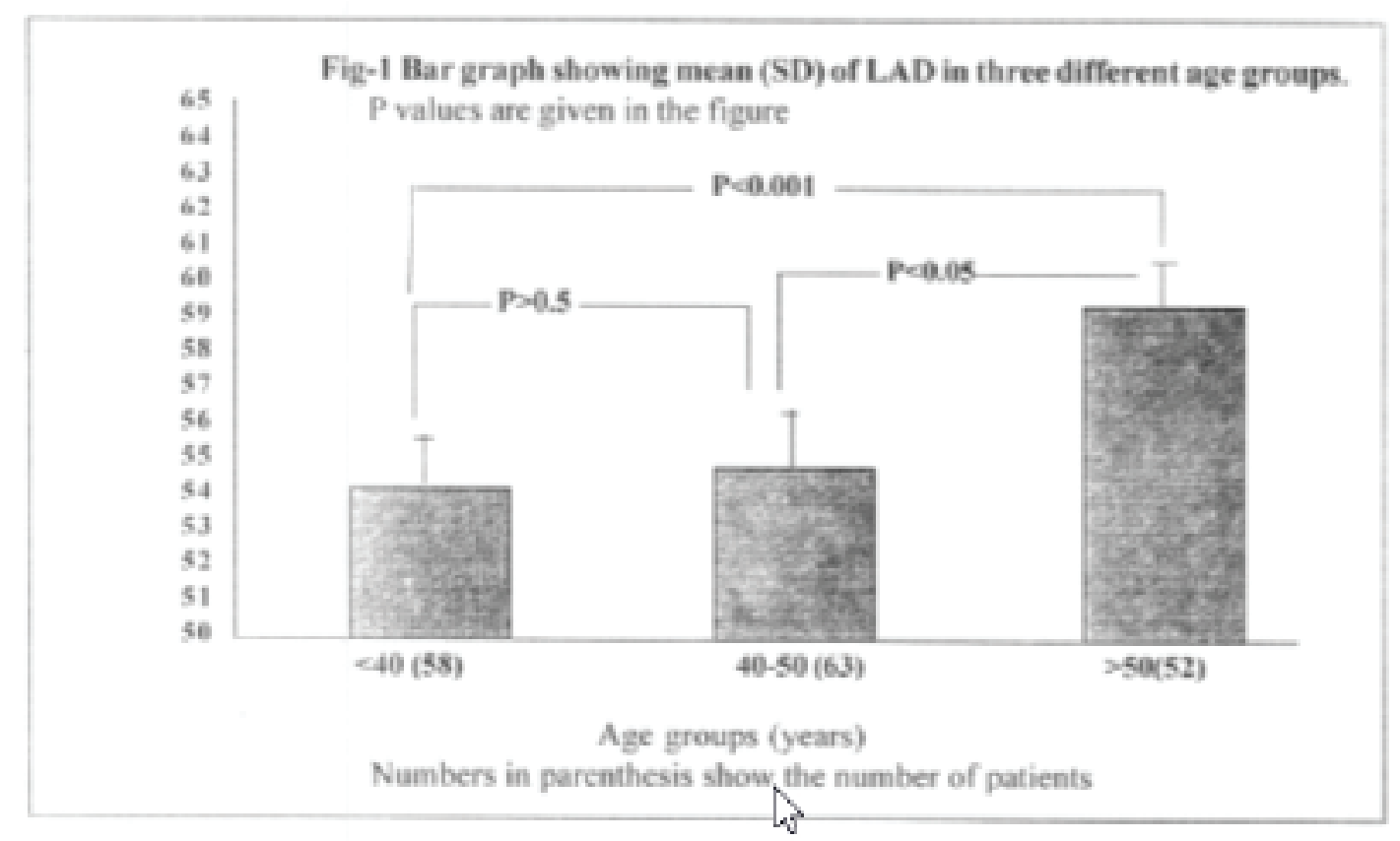

Correlation between LAD, age and MVA: When study subjects were stratified on the basis of heart rhythm, no correlation between LAD and age was found in both NSR and AF groups. While in the whole study subjects without heart rhythm stratification, a good positive correlation $(r=0.26, P<0.000)$ between LAD and age was found (Table-2). However a significant negative correlation

Between LAD and MVA ( $r=-0.28, P<0.05)$ was observed in NSR group, no correlation was found Between LAD and MVA in AF group and the whole study population, see the table 2 . 
- NEPALESE HEART JOURNAL •

Table 2 Linear regression and correlation analysis of LAD with age and MVA.

\begin{tabular}{|lll|}
\hline Correlation Analysis & Correlation Coefficient $(\mathbf{r})$ & $\mathbf{P}$ \\
LAD and Age & & \\
SR group & 0.11 & $\mathrm{NS}$ \\
AF group & 0.02 & $\mathrm{NS}$ \\
Whol & 0.26 & $<0.001$ \\
LAD and MVA & & \\
SR group & -0.28 & $<0.05$ \\
AF group & -0.14 & NS \\
Whole & -0.14 & NS \\
\hline
\end{tabular}

NS: Non Significant, LAD: Left atrial size, MVA: Mitral valve area, Other abbreviations as table 1.

Comparison of Age, MVA and LAD between NSR and AF group: Patients in AF were found older $(49 \pm 13.3$ years and $36.3+10.4$ years, $P<0.001)$ and had larger LAD $(58.8 \pm 9.5$ $\mathrm{mm}$ and $49.9 \pm 6.6 \mathrm{~mm}$,

$P<0.001)$ when compared with patients in NSR. MVA was not found different between AF and NSR groups (Table 3).

Table 3 Comparison of LAD, Age and MVA between NSR group and AF group

\begin{tabular}{|llll|}
\hline Patients & LAD $(\mathbf{m m})$ & Age $($ Yr. $)$ & MVA(CMP) \\
NSR group & $49.9 \pm 6.6$ & $36.3 \pm 10.4$ & $1.11 \pm 0.4$ \\
AF group & $58.8 \pm 9.5^{*}$ & $49.04 £ 13.4^{*}$ & $1.13 \pm 0.4$ \\
\hline
\end{tabular}

${ }^{*} P<0.001$ (abbreviations as previous tables)

\section{Discussion}

Rheumatic heart disease is still a problematic heart disease and a subject of major health concern in developing countries ${ }^{10}$. In developing countries, rheumatic heart disease is the most common cardiovascular disease in children and young adults and remain a major public health problem ${ }^{11}$. In developed countries, however it is becoming mainly a geriatric disease $^{12}$, rheumatic fever and rheumatic heart disease is still a problem in developed 
countries like USA ${ }^{13}$ Mitral valve stenosis is the commonest valvular lesion in rheumatic heart disease ${ }^{5.14}$. So we are mainly concerned on the study of rheumatic mitral stenosis and have tried to reveal the results of the evaluation of LAD on the basis of age and heart rhythm in this study.

Left atrial size enlarges in $\mathrm{MS}^{1.2}$ and previously it is reported that the left atrial size enlargement is an independent risk factor for the left atrial thrombi and it is an indication for anticoagulation therapy for MS patients, who are in NSR ${ }^{15}$. Recently in some studies, it is documented that left atrial size and AF are independent predictors of left atrial clot formation and systemic embolism in rheumatic heart disease ${ }^{7.8}$. Beside these clinical investigations, the evaluation of LA size on the basis of age and heart rhythm in MS patients is unavailable in those previous reports. One of the interesting findings of this study is that the size of left atrium is significantly enlarged in older age group when compared with middle age and young age group in MS patients, regardless of heart rhythm and gradual increment in the mean left atrial size among three age groups is observed in this study. Correlation analysis of the whole study population shows significant positive correlation between left atrial size and age, though the correlation was not established when separately calculated after patient stratification on the basis of heart rhythm, NSR and AF. Almost 43 years back, in one study, progressive cardiac enlargement was not observed with advancing age alone in either symptomatic or symptomatic rheumatic MS patients ${ }^{16}$. In that study cardiac chamber enlargement was determined by serial fluoroscopic examinations, while in this study LAD is measured by M-mode echocardiography in standard parasternal long axis view.

In this study, we observed no correlation between left atrial size and MVA. This finding is consisted with the finding of $1950 \mathrm{~s}^{5}$, although the left atrial size was determined by $\mathrm{x}$-ray views in that study. However good negative correlation between left atrial size and MVA was observed in NSR group alone, mean mitral valve area was not found different when compared between NSR and AF groups. In previous studies of MS patients it was reported that the patients with AF tended to be older ${ }^{4,17}$ and had larger left atrial size ${ }^{17}$. The result of this study consists with those previous findings.

Series of studies have approved the association between enlarged left atrial size, AF, age and left atrial clot formation and systemic embolism in rheumatic mitral stenosis ${ }^{7,8,18}$. 
Relationship between left atrial size enlargement and age and heart rhythm is not evaluated in those series of studies. The evaluation of relationship between left atrial size enlargement and age and heart rhythm in rheumatic mitral stenosis is ever first attempted in this study. Older patients have a tendency of having more enlarged LAD when compared with middle age and young age groups according to this study. Recently in one comparative study of MS patients larger LAD in older age group is documented ${ }^{19}$, Without providing the heart rhythm profile. The data of the study is on the favor of our findings.

However unavailable data of Mitral Regurgitation (MR) and left atrial pressure limited the findings of this study, the findings that patients in AF are older and have larger LAD than patients in NSR and in the whole study population, regardless of heart rhythm, older patients have larger LAD in the comparison of middle age and young patients and a significant positive correlation between LAD and age reveal the tendency of LAD enlargement with advance age in rheumatic mitral stenosis. Correlation between LAD and MVA in rheumatic MS does not establish according to the finding of this study.

\section{References}

1. IF Rahimtoola SH, Enriquee-Sarano M, Schaff HV, Frye RL, Mitral valve disease; mitral stenosis. Hurst's The Heart. International edition. McGraw-Hill, Health Professional Division. Vol.2, 1998, P 1789-1799.

2. Braunwald E. Valvular Heart Disease; mitral stenosis. Heart Disease, A textbook of cardiovascular medicine. Bang Lore, WB Saunders Company. Vol.2, 1997, P10071017.

3. Garca-Fernadez MA, Torecilla EG, Roman DS, Azevedo J, Bueno H, Moreno MM, Delcan JL.Left atrial appendage Doppler flow patterns: Implications or thrombus formation. Am Hearth J 1992, 124: 955-961.

4. Shan DJ, Demaria A, Kissolo J, Weyman A. Recommendations regarding quantitation in M-Mode echocardiography: results of a survey of echocardiographic measurements. Circulation 1978; 58: 1072-1083.

5. Wood P. An appreciation of mitral stenosis Br Med J 1954, 1: 1051-1063,11131124. 
6. Olesen $\mathrm{KH}$. The natural history of 271 patients with mitral stenosis under medical treatment. Br Heart J 1962; 24:349-357.

7. Goswami KC, Yadav R, Bhaskarrao M, Chopra A, Bahl UK, Talwar KK, Manchanda SC. Clinical and echocardiographic predictors of left atrial and left atrial appendage clot and spontaneous echo-contrast in patients with severe mitral stenosis. Indian Heart J 1999, 51: 636 (Abst.)

8. Singh M, Malhotra P, Rajkeshav R, Suresh N, Grover A, Varma JS, predictors of systemic embolism in rheumatic heart disease. Circulation 1998, Suppl I-700.

9. Faltera F, Pezzano A Jr, Fusco R, Mantero A, Corno R, Crivellaro W, De Chiara F, Vitali E, Cordini V, Magnani P, Pezzano A Sr. Measurement of mitral valve area in mitral stenosis: four echocardiographic methods compared with direct measurement of anatomic orifices. J Am Coll Cardiol 1996, 28: 1190-1197.

10.Limbu YR, Dali B, K.C. MB, Maskey A, Zhu HJ, Pan WM. Variation of age in clinically overt mitral stenosis patients from two different countries: A cross national study. Nepal J ScTech 2000, 2: 87-90.

11. Strategy for controlling rheumatic fever/rheumatic heart disease, with emphasis on primary prevention: memorandum from a joint $\mathrm{WHO} /$ meeting. Bull world health organ 1995:73:583-587.

12.Caroll JD, Feldman T. Percutaneouns mitral balloon valuotomy and the new demographic of mitral stenosis. JAMA 1993: 270:1731-1736.

13. Tany LY, Veasy LG, Minich LA, Shaddy RE, Ruttemberg HO, Orsmond GS. Is rheumatic fever still a problem in the United States experience with 411 consecutive cases. Circulation 1998; Suppl: 1-14.

14. Roberts WC, Morphologic features of the normal and abnormal mitral valves. Am J Cardiol 1983: 51:1005-1028.

15. Canradic C, Schall R. Left atrial size - A risk factor for the left atrial thrombi in mitral stenosis. Clin Cardiol 1995; 18:518-120. 
16. Magida MG, Streitteld FH. The natural history of rheumatic heart disease in the third, fourth and fifth decades of life. Circulation 1957; 16:713-722.

17.Limbu YR, Shen XD, Pan CZ, Shi YF, Chen HZ. Assessment of mitral valve volume by quantitative three-dimensional echocardiography in patients with rheumatic mitral valve stenosis. Clin Cardiol 1998: 21:415-418.

18.Coulshed N, Epstein EJ, McKendrick CS, Galloway RW, Walker E. Systemic embolism in mitral valve disease. Br Heart J 1970; 32:26-34.

19. Eltchaninoff H, Arora R, Rajgopal S, Chandra S, Danis, Bhat A, Rath P, Cribier A. Comparative indications, baseline characteristics and results of percutaneous mechanical mitral commissurotomy in western and developing countries. J Am Coll Cardiol 2000; 35: Suppl A, 525 A (Abst.) 